\title{
An Overview of Digital Twin Concept for Key Components of Renewable Energy Systems
}

\author{
Qiying $\mathrm{Li}^{1,2}$ and Yunze $\mathrm{He}^{2,{ }^{*}}$ \\ ${ }^{1}$ College of Electrical and Power Engineering, Taiyuan University of Technology, Taiyuan, 030002, China \\ ${ }^{2}$ College of Electrical and Information Engineering, Hunan University, Changsha, 410082, China
}

\begin{abstract}
Renewable energy $(R E)$ is green and low-carbon energy, which can not only protect the environment, promote the technological diversification of the energy supply system, accelerate the adjustment of energy structure, but also has important significance for the sustainable development of economy. With the increasing complexity of the problems of renewable energy system asset management and ensuring the operational reliability of electric power equipment, it's necessary to establish remote, online, reliable monitoring and inspection techniques for the state evaluation of electrical equipment during the full life cycle. In order to meet these demands, the digital twin is a very suitable technology. In recent years, there are numerous scientific papers demonstrating DT's capabilities in virtual simulation, condition monitoring (CM), power optimization and fault diagnosis for RE generation systems, transmission and transformation equipment and storage systems. The majority of the research focusing on product design, maintenance of operation, condition monitoring and fault decision-making has provided many valuable contributions to academia and industrial fields. Nevertheless, all this valuable information is scattered over many literatures and it is lack of systematic generalization. In this article, different applications of DT technology in RE system are analyzed, advanced methods and theories are summarized comprehensively, and the development trend of DT technology in renewable energy system in the future is introduced.
\end{abstract}

Keywords: Digital twin (DT), Condition monitoring (CM), Life cycle, Renewable energy (RE), Industrial Internet of Things (IloT).

\section{INTRODUCTION}

Renewable energy (RE) not only protects the environment but also variegate the power generation technology, which contains wind and solar energy and emerging marine renewable energy (MRE). In general, $\mathrm{RE}$ system is of great complexity, and includes RE generation, transmission, transformation and storage systems [1].

Wind power generation technology is the extensive applied RE generation technology at present, but its cost of operation and maintenance is high [2, 3]. In order to reduce the maintenance cost and shorten the downtime, it is necessary to improve the reliability of the key equipment for fan power generation and improve the maintenance strategy of equipment to predict the failure [4]. The life cycle of power equipment such as power transformer, power electronic module and high-voltage insulated cables in RE transmission and transformation equipment includes design, production, installation and operation process [5]. Monitoring and status evaluation of the whole life cycle can improve the reliability of power equipment operation. The physical process of dynamic charging and discharging may occur in RE storage system [6]. It

*Address correspondence to this author at the College of Electrical and Information Engineering, Hunan University, Changsha, 410082, China;

Tel: +86 13467698133; E-mail: yhe@vip.163.com is very important to measure battery capacity and evaluate battery performance degradation to ensure operation reliability and reduce the risk of host system downtime. As an emerging power equipment status monitoring and virtual simulation technology, digital twin (DT) integrates the Internet of Things (loT), big data analysis, artificial intelligence and other advanced technology [7], and can be applied to different life cycle of electrical equipment industrial applications [8]. At the same time, DT can also build a parameterized virtual model of physical objects or physical processes to simulate the ultimate working state of power equipment and obtain its ultimate parameters [9]. DT is well suited to improve the operational reliability of renewable energy systems and reduce operation and maintenance costs.

For the past few years, many documents have demonstrated the application ability of DT technology in virtual simulation, power optimization, $\mathrm{CM}$ and fault diagnosis. Most of the work is focused on product design, maintenance of operation, condition monitoring and fault decision-making. This paper introduced the various applications of DT technology in RE systems. The advanced applications of DT technology in representative RE fields are reviewed. The development trend, advantages and disadvantages of DT technology are discussed. The Internet of Things (IoT) is a system of smart devices that share and collect large amounts of data, sending the collected 
data to a cloud platform for various analysis and processing, and then providing the results to the users of the service terminal. The Industrial Internet of Things (IloT) can be seen as a specific application of the crop networking vision, with the main goal of increasing automation and productivity in industrial processes [10]. The development of industrial Internet of Things technology provides a reliable data management platform and automatic operation tool for DT technology in the application of renewable energy system. In this article, the relationship between industrial Internet of Things, DT technology and renewable energy systems is also discussed.

The rest of the article is arranged as follow: First, the basic concepts of DT technology are presented in section 2; Next, the developments of DT technology in RE generation system, RE transmission and transformation system, and RE storage system are reviewed in section 3, 4 and 5, respectively; Then, the summaries, technical advantages and challenges, and development trends are put forward in section 6; Finally, the conclusion is drawn in section 7 .

\section{DIGITAL TWIN}

The DT is an integrated system that can simulate, monitor, calculate, regulate, and control the system status and process. It has the characteristics of individualization, high efficiency and highly quasi-real. In addition, the DT is developed by data acquisition, virtual manufacturing technologies, based on the control, computation and communication units [11]. There are three main components in the DT system, the physical space, the digital space and the information processing layer that connects two spaces. The system has the characteristics of data-driven, intelligent perception, virtual reality mapping and cooperation interactive [12-14].
DT technology can use a variety of sensors to measure the real-time parameters of physical entities, realize data interaction between physical space and virtual space through the Industrial Internet of Things, establish simulation digital model in virtual space, and realize dynamic simulation of the system. The artificial intelligence algorithm is used to process dynamic simulation data and monitor the status of physical entities in real time. Digital twin technology allows not only to increase high voltage electrical equipment technical state identification accuracy but also to establish hidden relations between various parameters and to collect new practical knowledge using Big Data analysis and machine learning algorithms [9]. The general idea and further applications of digital twin concept are depicted by Figure 1 . In industrial applications, DT technology can be used to build a virtual entity for the life cycle of the product for dynamic simulation and data processing, consistency checking of the design results in design intent, found unexpected don't merit, improve production efficiency, reduce costs, the products in a predictive maintenance, condition monitoring and fault diagnosis, etc. The relationship of DT technology and product life cycle of each phase is shown in Figure 2.

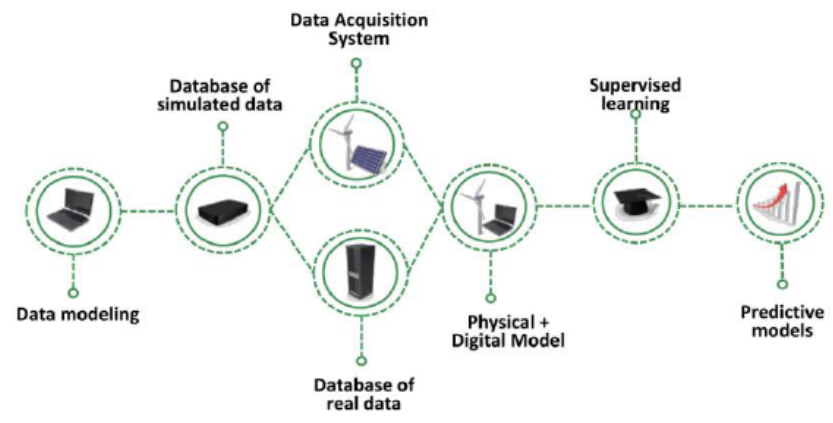

Figure 1: Digital twin constructing technology [9].
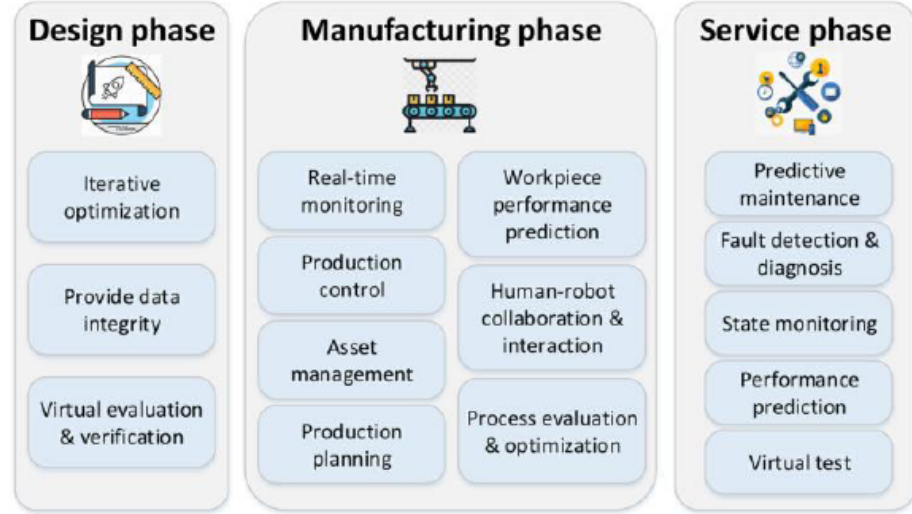

Retire phase

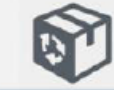

Require deeper research

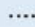




\section{DIGITAL TWIN IN RE GENERATION SYSTEM}

Renewable energy generation system mainly includes wind RE, solar RE and MRE generation systems. And with the development of RE technology, there are more and more countries have applied wave energy, a kind of MRE, to generate electric energy. The developments of DT technology in wind RE, solar RE and Marine RE generation systems are reviewed in section $3.1,3.2$ and 3.3 , respectively.

\subsection{Wind RE}

Wind power generation technology has been more widely used in renewable energy systems than other power generation technologies because of its lower cost and largescale development conditions [15, 16]. Wind power equipment is mainly composed of onshore and offshore wind turbines.

\subsubsection{Onshore Wind Turbines}

The digital twin, which track the life cycle of physical systems, is increasingly popular. The concept of DT technology is used to bridge the modeling and measurement domains so that real-time measurements from physical systems can be communicated to digital systems, and this information can be analyzed through a numerical model to estimate the state of the system and potentially predict its development. Kalman filters are an example of a technique that can be used. It combines system models with actual measurements to predict additional variables through numerical models, such as parameters for locations where there are no measurements [17]. Kalman filter can be used to estimate the load of the wind turbine by using digital twin models to assess the fatigue life consumption of on-site turbines in real time, performing condition monitoring, or assessing the load of a dedicated control strategy. The models are fast and can be run online. Main components of the model are shown in Figure 3.

As shown in [18], F, Pimenta et al. established a numerical model of an onshore wind turbine using DT technology. The control mechanism was calibrated using manufacturer catalog data, and the aerodynamic characteristics of different blade sections and the structural response under different operating conditions were calculated. This model can predict thrust and power output appropriately.

\subsubsection{Offshore Wind Turbines}

With the development of wind power technology, the proportion of offshore wind turbines is gradually increasing. Offshore wind can capture more energy, reduce visual impact and be more easily transported than onshore wind turbines. However, offshore wind turbines also face serious challenges. When it comes to turbines, where operating and maintenance costs are a significant part of the budget, lower costs will give wind plans more incentive to explore and invest. By optimizing maintenance strategies, the reliability of critical parts of the turbine can be improved, reducing costly turbine downtime and thereby reducing operating and maintenance (O\&M) costs [19]. As shown in

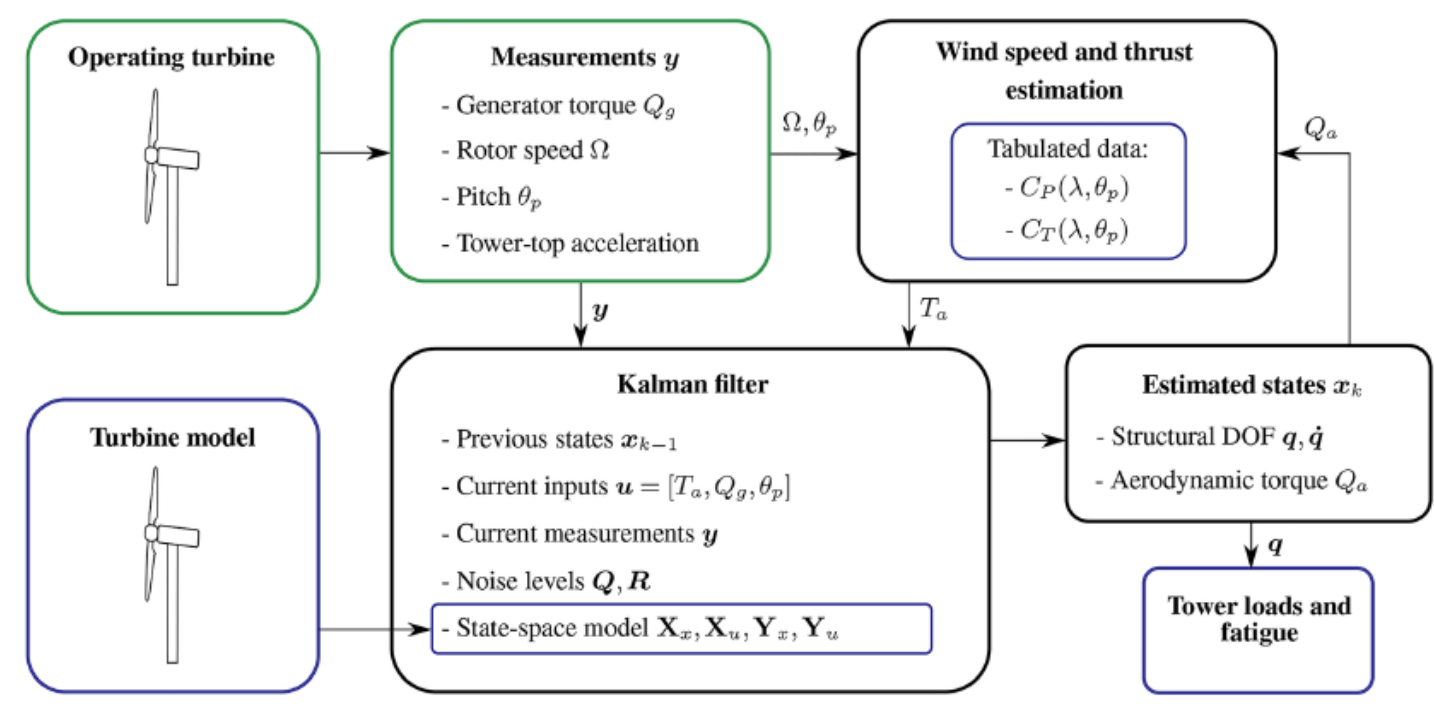

Figure 3: Main components of the model: wind turbine measurements and a turbine model are combined to estimate tower loads. A wind speed estimator and a Kalman filter algorithm are used in the estimation. Turbine model dependencies are framed in blue [17]. 


\section{Updated Scenario Optimised Scenario Reduction [\%]}

\begin{tabular}{llll} 
Repair Costs [M€/yr] & 9.52 & 8.52 & 10.43 \\
\hline Rev. Losses [M€/yr] & 1.64 & 1.57 & 4.21 \\
\hline Total Effort [M€/yr] & 11.16 & 10.10 & 9.51 \\
\hline Costs per kWh [c€/kWh] & 3.35 & 3.00 & 10.58
\end{tabular}

Figure 4: O\&M cost reduction in results of O\&M strategy optimization [4].

Figure 4, an optimized O\&M strategy will reduce repair costs by $10.43 \%$ and increase the profit by $4.21 \%$ with a net savings of Eurodollar (EUR) 1.06 million per year.

As shown in [4], Krishnamoorthi Sivalingam et al. proposed a new physics-based method for predicting the residual life of electrical components, which can improve the reliability of key equipment and reduce the cost of operation and maintenance. The numerical model used in the wind turbine design phase $(5 \mathrm{MW}$ NREL FAST model) can estimate degradation and residual life. For key components of wind turbines, they placed virtual sensors in a $5 \mathrm{MW}$ numerical turbine in virtual space to predict Remaining Useful Life (RUL) and compare optimal operation and maintenance strategies, from which the failure risk of each failure mode was derived. The method has been implemented in fixed and floating wind farm applications by using a $5 \mathrm{MW}$ NREL virtual wind generator and digital twin technology. A schematic diagram of digital twin technology platform is shown in Figure $\mathbf{5}$ for this method.

The above researches show that DT technology can predict the remaining life of key parts of wind turbines, improve maintenance strategies, evaluate the operating status of generators and thus reduce the operation and maintenance costs of wind RE. However, the degree of DT technology to reduce operation and maintenance costs needs to be further researched.

\subsection{Solar RE}

As solar power generation technology is developing rapidly, different forms of photovoltaic cells have been researched to meet the corresponding needs in solar power generation, which includes crystalline silicon and flexible solar cells, and other types of solar cells [20]. Among them, flexible solar cells can be applied to the aerospace industry due to their advantages of light weight and flexibility [20-23]. Nevertheless, the performance gains of these photovoltaic cells are limited by their low reliability. Therefore, it is necessary to improve the performance of photovoltaic cells. Improving the quality of the manufacturing process in the solar cell life cycle can be used as a means of producing high-performance, low-cost photovoltaic cells $[24,25]$.

As it is shown in [26], Feng-Que Pei et al. have proposed a high throughput measurement method based on DT and DTS (Digital twin shop floor) models, for process quality control of series solar cell

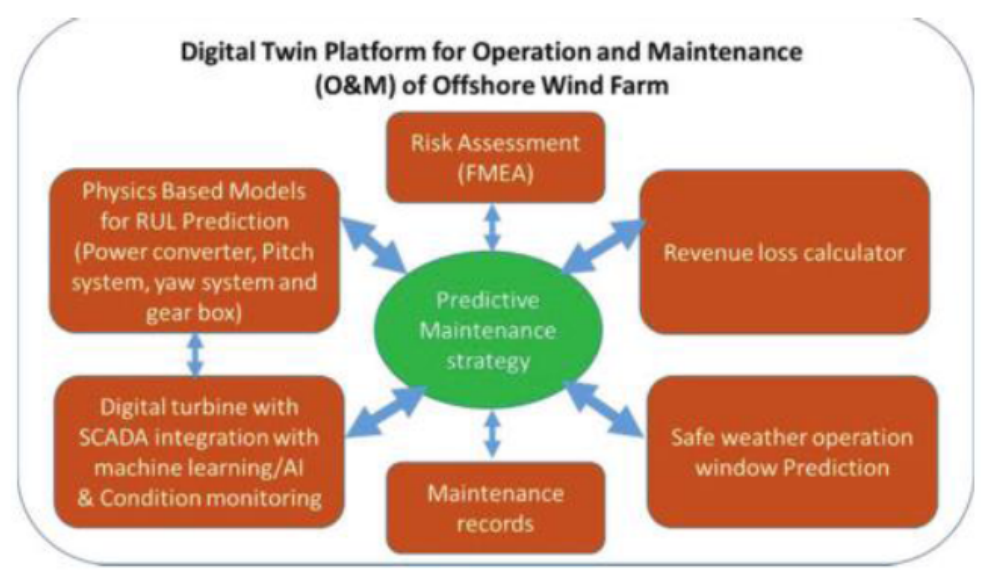

Figure 5: A simple schematic diagram of digital twin architecture for 5MW NREL virtual fixed and floating wind farm O\&M [4]. 
production line (SSCPL), and its performance was analyzed in detail. The self-organized model captures quality-related dynamic behaviors and maps these behaviors into virtual Spaces. Offline measurement, online training and testing, real-time monitoring and real-time configuration are realized through a series of analysis methods.

DT technology is also widely used in the service phase of solar generation life cycle. Due to the high construction cost of photovoltaic power plant, it is necessary to maintain the operation of the power generation equipment that has been built. As it is shown in [27], Ludmila Massel et al. discussed a digital twin construction method based on ontology engineering and established a mathematical model of photovoltaic power plant. This model can predict the actual time of equipment replacement or maintenance work in advance, saving the operating cost of the system. The model needs to gather information about the behavior of the system, such as weather conditions, equipment characteristics and so on. These data increased over time with a large amount of data, so Ludmila Massel et al. established a relational database to organize and store the data. Moreover, such an approach significantly reduces the time and labor costs required to perform iterative-incremental development cycles of the twin [28]. However, duplicate information may occur in data stores and the query efficiency is low.

In view of the increasing time-based data of mobile phones and the variability of weather conditions, as shown in [29], R.M. Asimov et al. introduced DT technology to establish PV models to monitor the conditions of solar power plants. Photovoltaic (PV) digital twin system consists of a PV mathematical model, a big data analysis engine and an artificial intelligence knowledge engine.

The PV mathematical model is central part of the digital twin system, which learns from monitoring data and converts an almost infinite amount of time series data into a fixed set of model variables (see Figure 6(a)) while conducting monitoring data validation. Big data analysis engine performs classification task using values of model variables and provide useful indicators of the system health (see Figure 6(b)). Artificial intelligence knowledge engine applies knowledge base rules to the health indicators to create system status reports and make decisions about required maintenance actions (see Figure 6(c)).

The above researches indicate that DT technology can play an important role in the manufacturing and service phases of the solar generation life cycle. Specifically, DT technology can not only monitor the manufacturing process of solar cells, to create highperformance, low-cost photovoltaic cells, it is also possible to conduct condition monitoring and simulation of the solar power plant, which can discover existing problems at the solar power plant and predict the actual timing of equipment replacement and maintenance. In addition, DT technology was also used in the development of solar car. As shown in [30], Luchang Bai et al. stimulate a solar car with the digital twin technology to accurately characterize energy to model these components of solar cars which are hard to formulate. With the development of DT technology, it's predictable that DT technology will be more and more applied in the life cycle of solar generation. DT technology may realize full traceability, real-time twoway sharing and information interaction of solar power generation in the future.

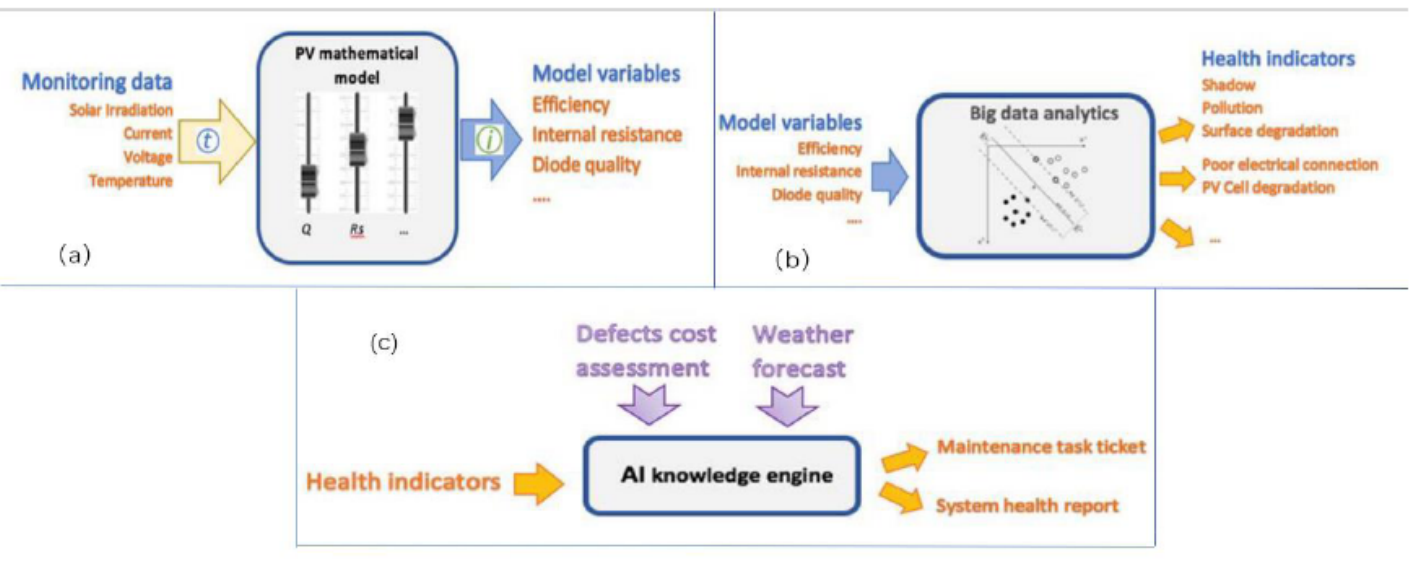

Figure 6: (a). PV Mathematical model; (b). Big data analysis engine; (c). Artificial intelligence knowledge engine [29]. 
IloT can provide loT sensors for renewable energy generation systems to monitor the efficient operation of the generator set. Taking photovoltaic power stations as an example, loT sensors can monitor the orientation and position information of solar panels in real time, and use IloT to transmit relevant data to the DT model in the cloud platform for analysis. According to the results, the solar panels are automatically steered to follow the sunlight to improve the efficiency of solar power generation.

\subsection{Marine RE}

While a lot of research has been done in solar and wind energy, wave energy is a relatively young field. There is less research in this area than in wind and solar power generation. However, with more than 70 percent of the earth's surface covered by oceans, wave power has great potential. Wave energy converter (WEC) can transform the energy generated by the waves into electric energy by utilizing some sort of power take-off system. Figure $\mathbf{7 ( a )}$ shows the construction of a type of WEC which is constituted by several power take-off (PTO) systems. Figure 7(b) shows the construction of a PTO system.
Compared with wind power, wave power systems operate in a harsher environment. Therefore, accurate and reliable wave power status monitoring is very important to optimize the operation cost and improve the reliability of power system. Wave energy is influenced by many factors, including wind speed, ambient temperature, wave speed, wavelength, and water density [33]. The analysis of these data is very important for the operation status monitoring of WEC. Artificial intelligence algorithm, Internet of Things and cloud computing platform are usually used to process the data. As shown in [34], Peng Qian et al. proposed a new wave power generation status monitoring system based on Internet of Things. In the monitoring system, a predictive model based on DT technology is used to simulate the data output of the WEC during normal operation. By comparing the actual output with the simulated output, we can judge whether the WEC is faulty. The deviation of the comparison results indicates that the WEC is faulty, and the fault information will be output. Figure 8 shows a schematic diagram of the data-driven condition monitoring system.
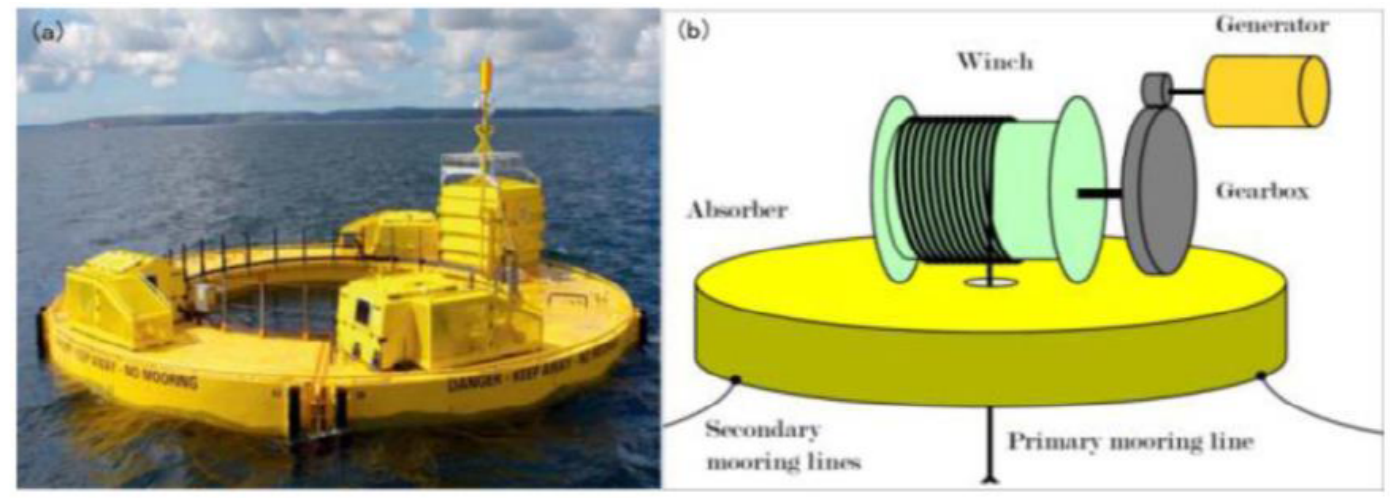

Figure 7: (a) The WEC at the FaBTest site [31]; (b) The structure of a PTO system [32].

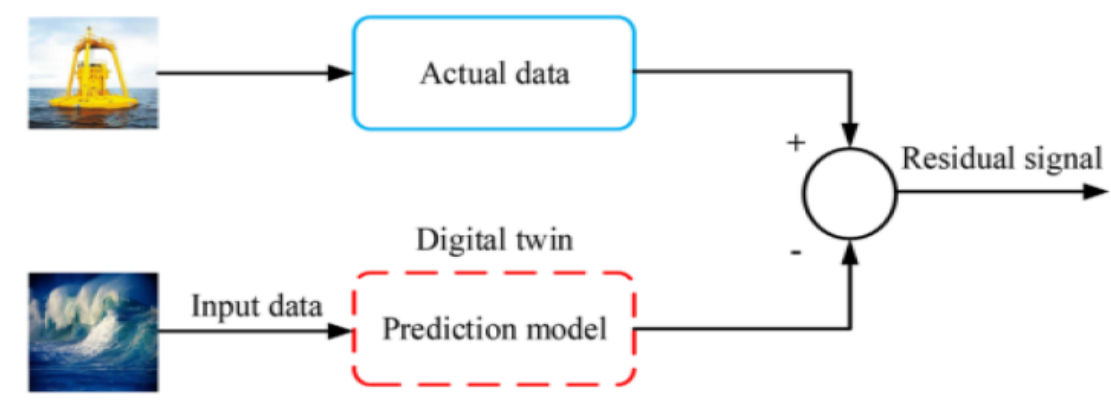

Figure 8: schematic diagram of the data-driven condition monitoring system [34]. 


\section{DIGITAL TWIN IN RE TRANSMISSION AND TRANSFORMATION EQUIPMENT}

As RE generation technology is developing rapidly, grid connected power generation is the development trend in the future. It depends on the transformers, Gas insulated switchgears (GIS) and power cables. The developments of DT technology in the CM of transformers, GISs, power cables are introduced in section $4.1,4.2,4.3$ and 4.4 , respectively.

\subsection{Transformer}

Transformers are the key devices in the power system because of the powerful ability for power supplying [35], and equipment failure will cause huge economic losses. With the development of various nondestructive testing technologies, various operating data, monitoring data, maintenance data and experimental data are constantly produced. These data reflect the operation status of power transformers from different aspects and to different degrees. However, the coupling, fuzziness and randomness of state information make it difficult to evaluate the state of power transformer [36]. Digital twin technology creates completely new approach for electrical equipment state estimation. A digital twin model could simulate the operation and maintenance process of transformers, and perform the state evaluation under various environments.

DT technology can be applied to power transformer status identification. As shown in [37], Ivan, E, Kolesnikov et al. through digital modeling of power transformers, used modern diagnostic methods in the LabView environment to test the data parameters of normal and abnormal operation conditions of transformers, including overload and overvoltage, and compared them with the corresponding parameters in reality, so as to detect and correct their accuracy. The model can collect and process a series of data of the sensor in continuous operation, simulate and check the transformer work, and put forward effective diagnosis suggestions for the transformer working state and prevent the emergency state. As shown in [36], YANG Yong et al. also proposed a method of applying DT technology to state assessment, which makes the simulation model closer to reality and guides the actual operation of power transformers through data interaction between virtual models and physical entities, and took $110 \mathrm{kV}$ power transformers as an example to evaluate this method. According to various test data and monitoring data, they set up multidimensional status evaluation index system of power transformer. The feasibility and effectiveness of the proposed method are verified by the calculation and evaluation of a $110 \mathrm{kV}$ transformer in Hubei province and the comparison between the calculation results and the actual state. The system framework is shown in Figure 9. Besides, DT technology is also used for voltage and current measuring transformers. As it is shown in [9], A.l. Khalyasmaa et al. introduced the experimental study of digital duplex technology of $110 \mathrm{kV}$ voltage and current measuring transformers based on actual power station. They built a mathematical model based on a complex technical diagnostic system for power transformers. In the mathematical model, a set of parameters is selected for each device for technical state analysis. The defects or limit state groups of different parts are defined by using the data obtained by online diagnosis methods of different technologies. This limit state cannot be determined by conventional diagnostic methods established in technical standards. Developed diagnostic system is depicted by Figure 10.

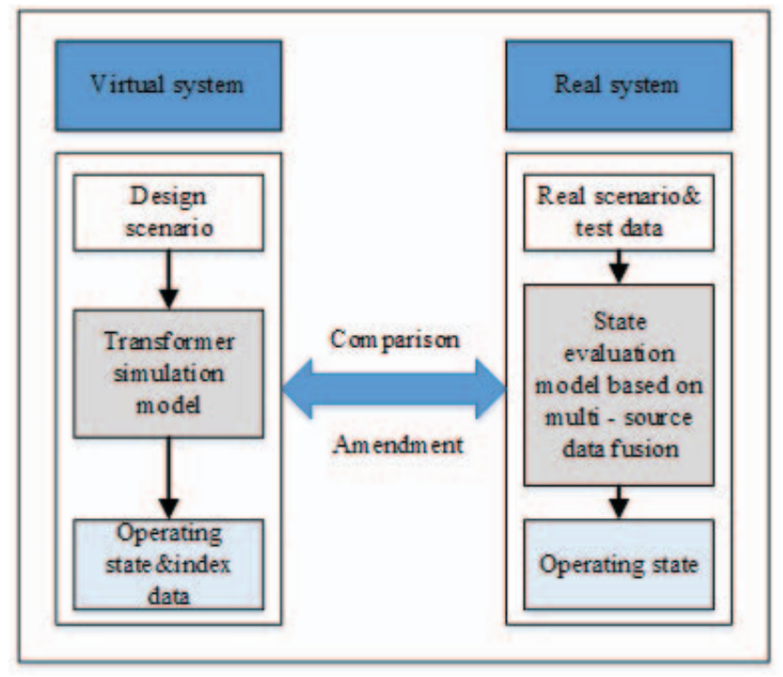

Figure 9: The framework of power transformer state evaluation system based on digital twin [36].

\subsection{Gas Insulated Switchgear}

GIS has been wildly used in the parts of transmission and distribution at power grid due to good insulating property and low floor space [38]. In [39], Zongmin Jiang et al. put forward the concept of "DMS" framework, which means that the practical application of DT technology mainly focuses on data, model and service. They built GIS Internet of Things based on this 


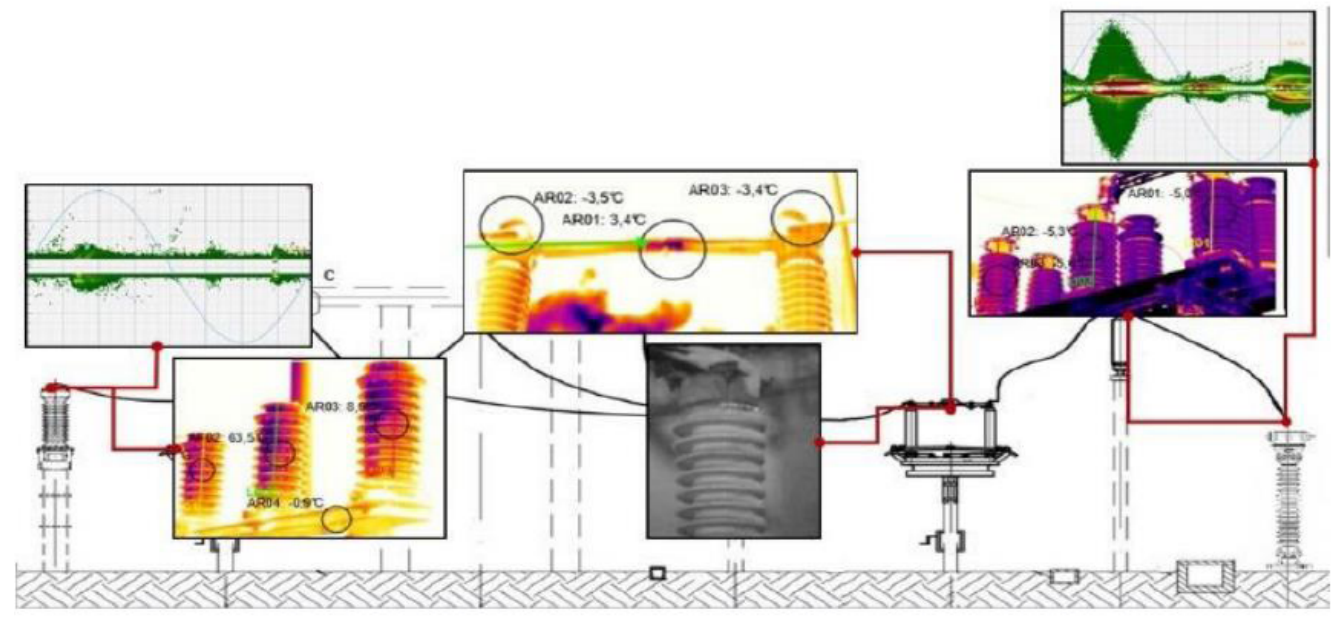

Figure 10: Electrical equipment digital twin diagnostic system realization [9].

framework, and realized high-resolution acquisition of device local state data as well as edge analysis and calculation. According to the requirements of intelligent business and real-time response of GIS, the DT of GIS is divided into GIS_P1 and GIS_P2. GIS_P1 is integrated acquisition device with outstanding computing capabilities for collection, monitoring and alarming of running state and parameters, and GIS_P2 is established on the cloud platform for PHM (Prognostics and Health Management), asset management, and predictive maintenance. GIS_P1 and GIS_P2 constitute the DT of GIS. Figure 11 describes the framework of GIS loT system based on DT.

DT technology is a combination of virtual entities and real physical objects [40]. The application of DT technology in GIS Internet of Things system promotes the development of GIS simulation technology. In addition, it is helpful to realize remote on-line monitoring, prediction, health management, fault diagnosis and intelligent fault decision of GIS equipment. GIS equipment can build GIS digital simulation model by combining DT technology with historical data stored in the cloud platform of the Internet of Things to simulate the normal operation of a GIS system, compare the output data with the actual real-time data, and analyze the working status of GIS system. The DT not only promotes the intelligence of GIS equipment but also boosts customer experience. The establishment of GIS Internet of Things system realizes the wireless interconnection between physical components, so that people can observe the working status and fault analysis of GIS remotely through various intelligent devices connected to the Internet of Things.

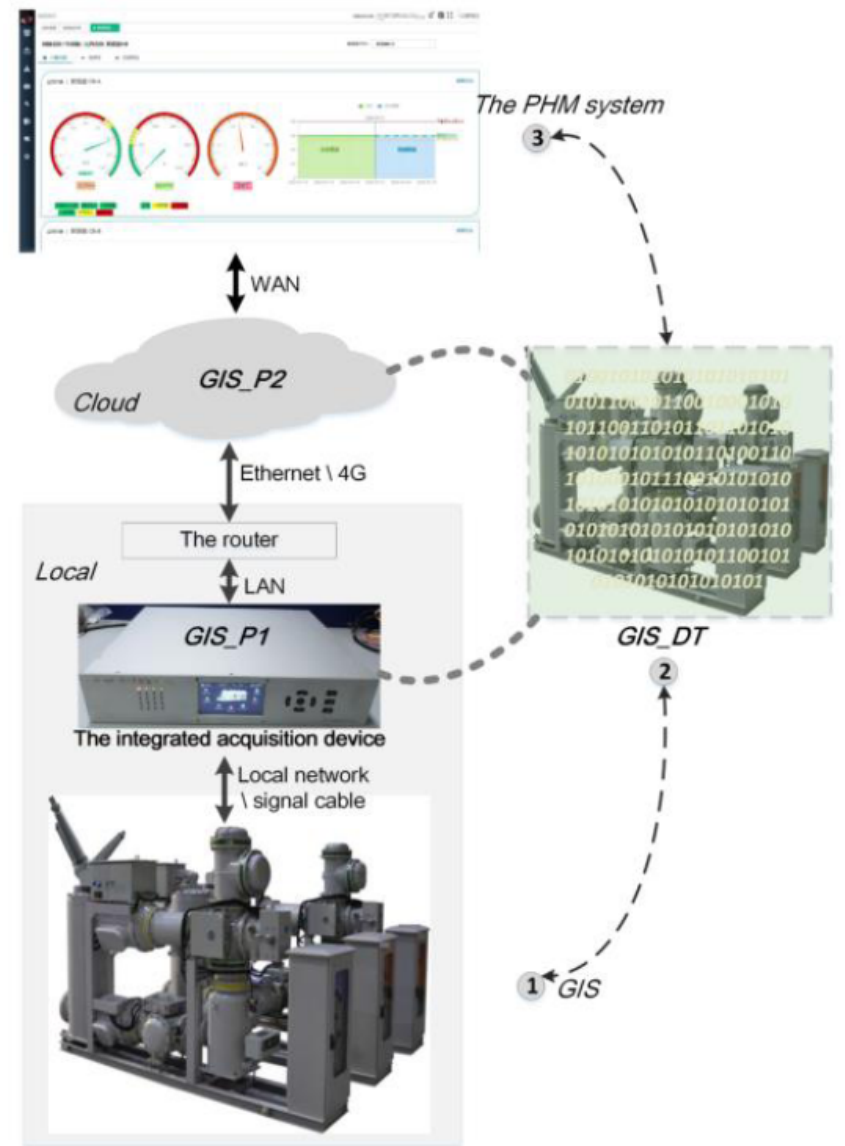

Figure 11: the framework of GIS IoT system based on DT [39].

The above research mainly describes the mapping of physical entities and virtual entities (a series of data) by GIS system through DT technology, but the establishment of GIS digital model and the method of fault analysis are not introduced. At present, there are few application examples of DT technology in GIS 
system. DT technology has great research potential in GIS system condition monitoring, prediction, health management and fault diagnosis methods.

\subsection{Power Cable}

The safety of cable is directly related to the transmission and distribution of urban electricity, which is an important part of urban power transmission and distribution system and closely related to people's lives. Cable failure can be caused by many factors [41-43], so the maintenance of the cable needs to be checked regularly. It is a complicated process for cable inspection including UV defect inspection, insulation inspection and clamp inspection and so on. And most of the cable inspection work is done manually, which takes a long time and is less efficient.

As it is shown in [44], O. Kähler et al. proposed a multi-mode sensor automatic detection system using the DT model. The system makes it possible for the staff to remote online browse recorded data and cable status through high-level organization of sensor data and detection results. And the DT model consists of a semantically segmented $3 D$ point cloud and the 3D positions of detection components, where each component comes with a list of images and their respective detailed 2D positions. The purpose of semantic segmentation is to distinguish the infrastructure of power equipment from the surrounding environment. The DT model is shown in Figure 12. The applications of DT technology in three sensor detection directions of cable detection: insulation inspection, fixture inspection and ultraviolet (UV) defect detection are introduced below.

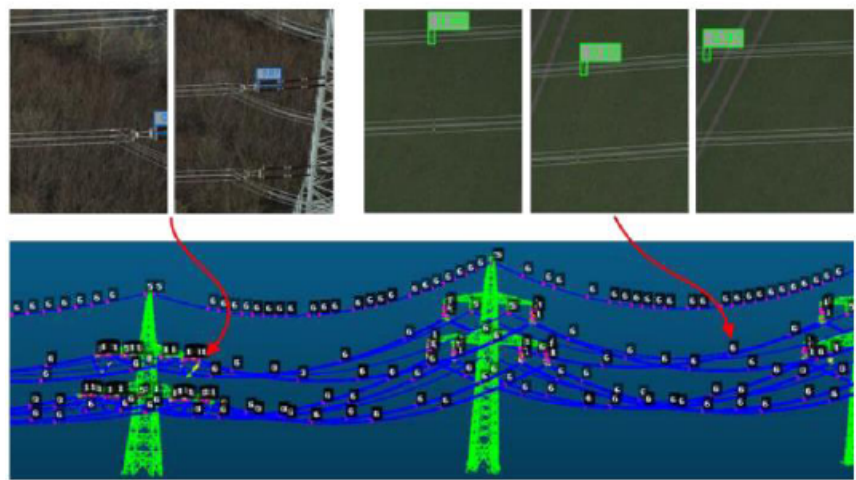

Figure 12: Sample of the digital twin representation showing a semantically segmented 3D point cloud of the infrastructure, detected components and sample images of these components [44].

Damage to insulators is usually detected by visual inspection by properly trained personnel. High resolution RGB (red, green, blue) images and trained 2D image classifiers can be similarly used in detection systems. In insulation detection, the authors et al. utilized unified detection in digital twin representation to collect $R G B$ images around the detection body and classify them through a deep learning-based classification network for online fault detection by staff. The heating failure of the clamp can be evaluated by infrared spectrum measurement. In the automated detection system, because the digital twin image incorporates the list of components, the staff can project the corresponding 3D position into the thermal infrared image and further analyze the clamp state from the extract as shown in Figure 13. A partial discharge may occur in the sharp part of a high voltage line with strong electric field variation. A partial discharge will lead to cable damage and cause the cable to experience a corona phenomenon. Besides, the

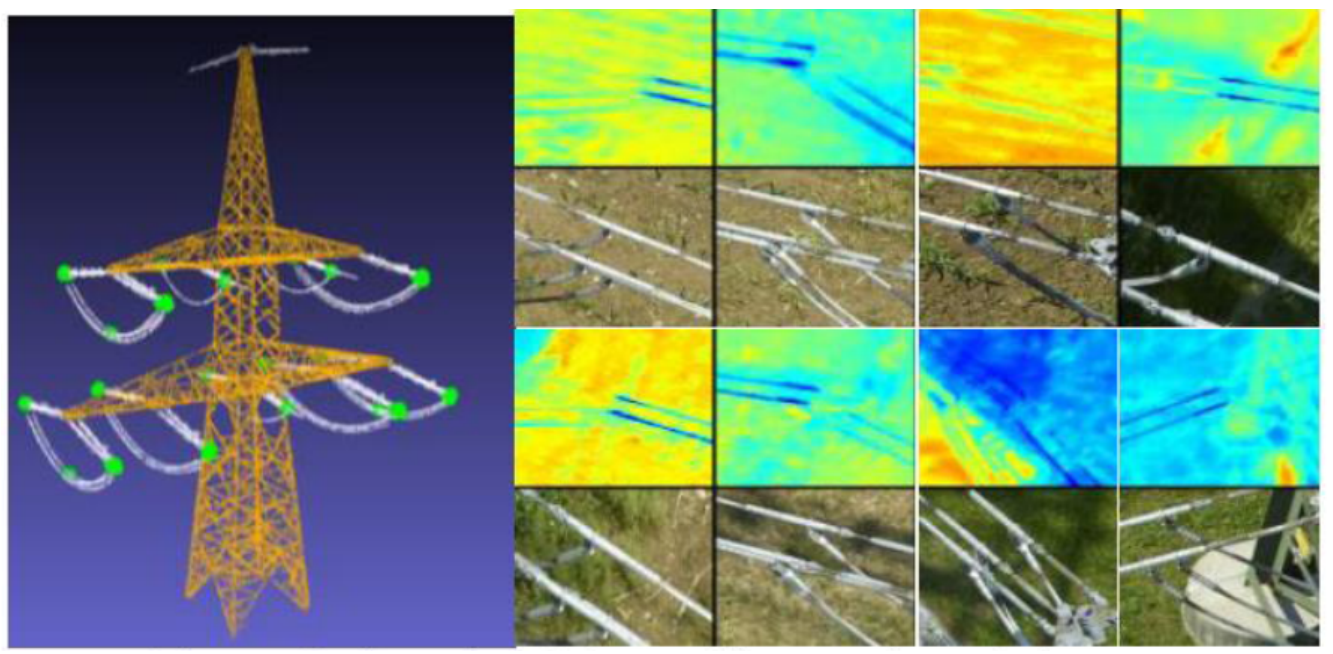

Figure 13: Sample of thermal inspection of clamps and its digital twin representation [44]. 
ionization of air will further corrode the cable and seriously threaten the normal operation of the cable. In UV defect detection, corona discharge of cable can be detected by using UV sensitive camera, and bright spots will appear in the faulty part. From the bright spots captured by the camera, the 3D position hypothesis of the partial discharge along the observed position can be obtained. A sample of partial discharges clustered in 3D is shown in Figure 14. Workers can look for nearby infrastructure elements in the digital twin to determine the location and cause of the failure.

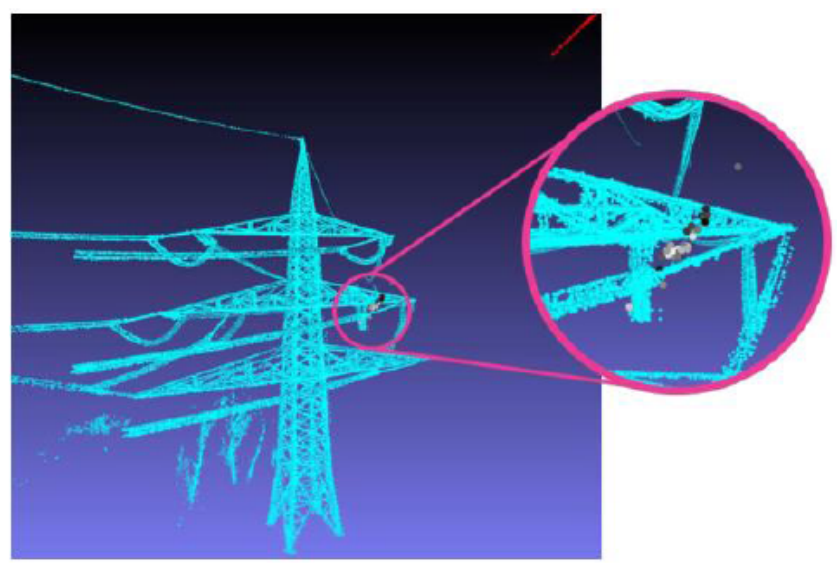

Figure 14: Digital twin representation of sample of partial discharges clustered in 3D [44].

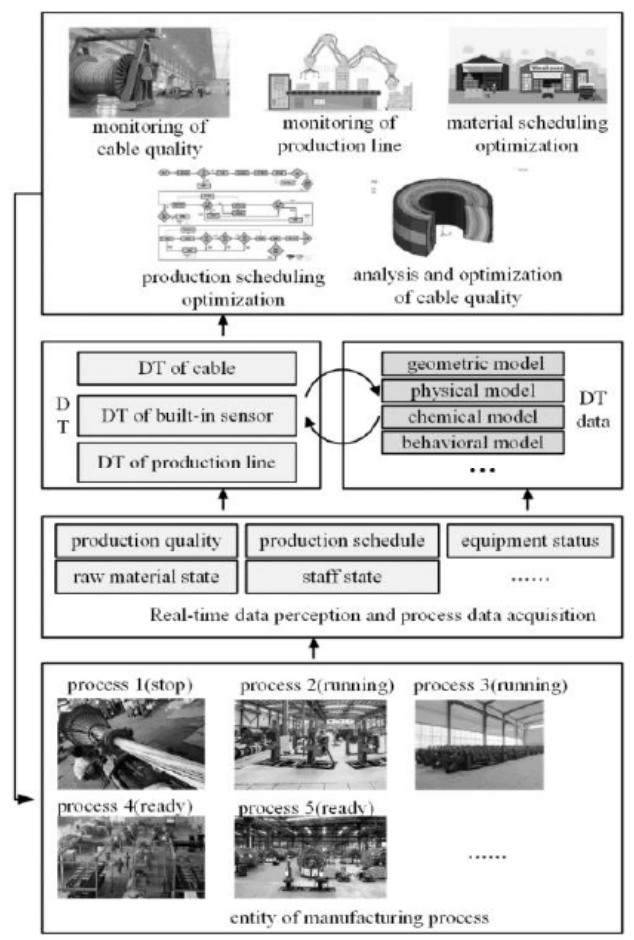

This paper [44] mainly studies the application of the DT model in cable fault detection and establishes a very perfect multi-mode sensor automatic monitoring system. However, DT technology can also intelligently manage the cable life cycle including design, production, operation and maintenance phases. Weisheng $\mathrm{He}$ et al. elaborated on this in [45]. In the design stage of the cable, the cable design parameters based on the MBD (model-based definition) model are added to the cable 3D digital model, and the geometric characteristics, physical and chemical properties of the cable and various physical models such as electrical model, mechanical stress model, thermal model and material model are fully considered. DT technology, which integrates advanced technologies such as Internet of Things, artificial intelligence and big data analysis, is fully utilized for comparative analysis of historical data of high-voltage cables with the same design, and iterative optimization of the model is carried out. At the same time, DT technology can also use interactive user feedback based on user experience, in the virtual world to constantly improve the product design model. During the manufacturing stage of the cable, the measured data can be transmitted to the corresponding digital twin model, and the measured value can be compared with the design value. According to the comparison results, the production process is optimized, the production quality

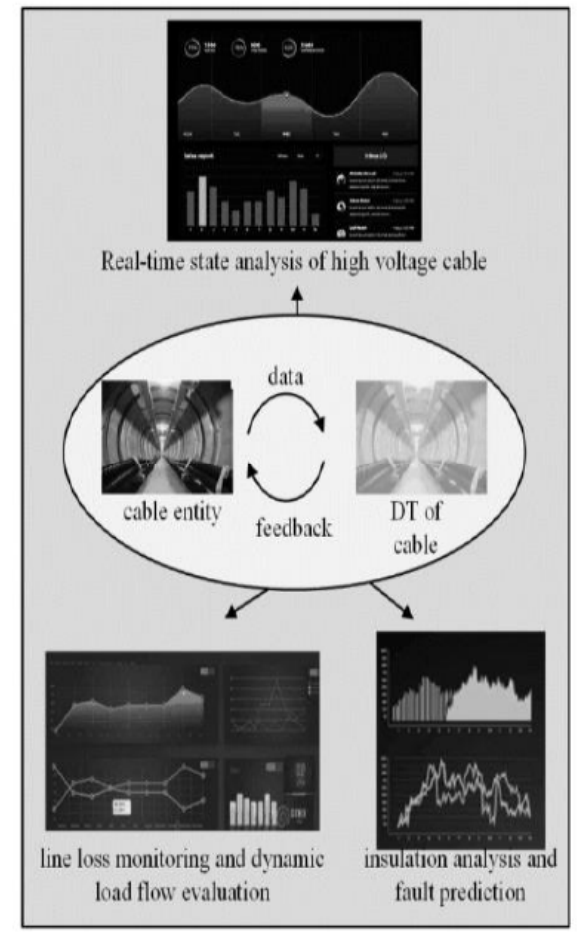

Figure 15: (a) Schematic diagram of DT implementation high voltage cable(left); (b) Schematic diagram of the basic framework of operation and maintenance Service based on DT (right) [45]. 
and production schedule are predicted, and the prediction analysis results are fed back to the manufacturing physical entity to realize the combination of virtual model and real physical entity. The schematic diagram of the DT implementation of the high voltage cable manufacturing process is shown in Figure 15(a). In the phase of operation and maintenance, the basic virtual digital model of cable is established based on DT technology. Data such as voltage, current and partial discharge (PD) in cable can be detected and updated in real time to ensure the synchronization between virtual model and physical entity. DT can monitor the status of cable operation according to these data. Figure 15(b) shows the cable operation and maintenance service framework based on DT technique.

The extensive applications of DT technology in cables greatly reduces the workload of inspection personnel and improves the efficiency of inspection. In addition, due to the rapid development of power system, the complexity of power lines is becoming higher and higher, which increases the difficulty of power flow calculation. The development of automatic monitoring system based on DT technology can reduce the workload of power flow calculation in some regions by monitoring and analyzing cable operating parameters such as voltage and current directly. The application example of DT technology in cable life cycle can also be extended to other transmission and transformation equipment, and the development of related fields needs further research.

The Industrial Internet of Things can provide a remote online data analysis cloud platform for the applications of DT technology in power transmission and transformation equipment introduced above. IoT sensors are installed on power transmission and conversion devices in accordance with certain rules to collect device parameter information in real time. This information is transmitted to the DT virtual models in the cloud platform over the wireless network. Most of the equipment can monitor the status and automatically process fault information through virtual simulation of DT models. Other equipment, such as surface defect monitoring of insulators, can also assist the staff to carry out visual analysis and fault decision through three-dimensional display of DT models.

\section{DIGITAL TWIN IN RE STORAGE SYSTEM}

Renewable energy, such as wind energy, solar energy and wave energy, is greatly influenced by the environment, and the power output is intermittent and random. The direct connection of these power generation systems to the grid may lead to the fluctuation of grid voltage and reduce power quality. The development and application of RE storage system can solve this problem, so the RE storage system plays an important role in RE grid-connected power generation. In many energy storage systems, electrochemical batteries have great application potential in power grid energy storage system because of its advantages of easy installation, fast response speed and modularization. Besides, the electricity generated by renewable energy systems can also be stored in electrochemical cells as a power source for vehicles such as cars. Because long-term stability, high-energy density, safety, and low cost are common to developing batteries for both automotive and grid applications, considerable synergy should exist between the two areas, although there will be certain differences [46].

\subsection{Lithium-Ion Batteries}

Lithium-ion batteries ( LIB ) are an important technology for achieving low-carbon goals, with applications ranging from electric cars to grid-scale energy storage to balance electricity from renewable sources such as wind and solar [47]. However, lithiumion batteries are also faced with the problems of limited energy density, short life and high cost. How to evaluate the performance of lithium-ion batteries in the real environment is crucial to improving the reliability and stability of energy storage systems [48]. Some irreversible electrochemical reactions will occur in the process of repeated charging and discharging of lithium-ion batteries, which will lead to the gradual deterioration of their performance over time. Evaluating LIB performance degradation is of great importance to ensure operational reliability and reduce the risk of downtime [6].

As for the application of DT technology in performance degradation of lithium-ion batteries, in [6], $\mathrm{Qu}, \mathrm{X}$ et al established the DT model on the basis of simulation real information platform based on advanced sensors, high-performance computers and intelligent data analysis technology. The maximum available capacity is estimated by simulating the virtual complete discharge process of digital dual crystal lithium-ion batteries. Based on the DT model of the lithium-ion battery, the discharge process of the battery can be easily simulated by on-line voltage measurement. In addition, this battery-level DT model can be extended to a LIB pack to improve the timeliness of battery 


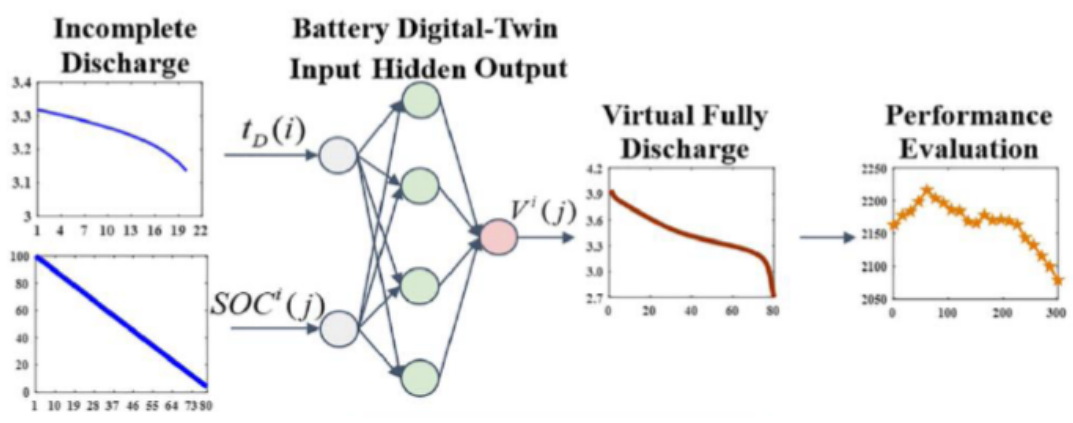

Figure 16: Schematic diagram of proposed degradation evaluation model [6].

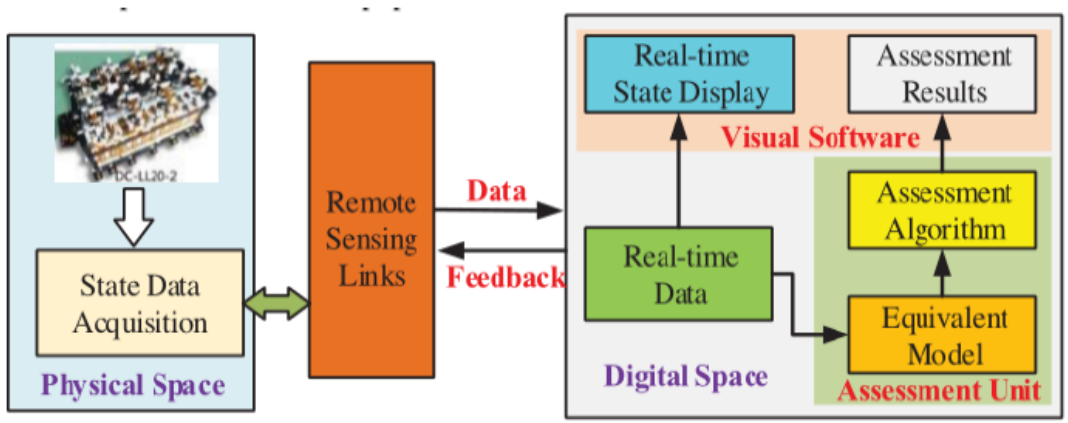

Figure 17: Architecture of the Digital Twin Platform [49].

maintenance and facilitate the reasonable planning of electric energy. A schematic diagram of the proposed degradation evaluation model is shown in Figure 16. In addition, Yu Peng et al established a DT platform based on low-cost modules and software development in [49] for performance degradation of spacecraft lithium-ion batteries, and conducted tests and verification. Architecture of the Digital Twin Platform is shown in Figure 17.

DT technology can also be applied throughout the whole battery life cycle. As shown in [50], Lukas Merkle et al. proposed a DT architecture for automotive battery system, on the basis of which digital services can be established for various stakeholders in the battery system life cycle.

The above studies show that DT technology can realize the digitalization of lithium-ion power battery, evaluate the performance degradation of lithium-ion batteries and serve the whole life cycle of battery system. The next research direction is to establish a complete power battery life cycle monitoring system based on DT technology.

\subsection{Fuel Cells}

Because of their high energy conversion efficiency and cleanliness, fuel cells have broad application prospects in the fields of proton exchange membrane fuel cells (PEMFCs) for electric vehicles and solid oxide fuel cells (SOFCs) for distributed power generation systems.

Compared with pure battery vehicles, fuel cell vehicles have the advantages of fast charging speed and long driving range. However, the reliability and durability of PEMFC technology still need to be improved [51]. A schematic of the PEMFC system is shown in Figure 18. Bowen Wang et al. proposed a data-driven proxy modeling framework in [52] and compared it with the simulation results of physical models. The agent model realizes the multi-physicalresolved digital twinning of PEMFC, which can be used to know the healthy operating range of the battery in advance and be embedded into the digital twinning module of PEMFC control system. As it is shown in [53], Bowen Wang et al. proposed a data-driven proxy modeling framework and compared it with the simulation results of physical models. The agent model realizes the multi-physical resolution digital twinning of PEMFC, which can be used to know the healthy operating range of the battery in advance and be embedded into the digital twinning module of PEMFC control system. Jia-lin Kang et al. proposed a fault diagnosis method based on DT technology for PEMFC 
fault detection and verified its feasibility through simulation results. In this method, the actual data of PEMFC is collected by sensors and updated in real time. The collected data is sent to the DT model based on the dynamic model of PEMFC for simulation, and the residual vector is detected and evaluated for fault diagnosis. When the residual vector checks the fault detection threshold, fault isolation is performed.
Implementation of DT-based fault diagnosis in PEMFC systems is shown in Figure 19.

PEMFCs are developed primarily for vehicular applications because they are lightweight systems that operate at approximately $80^{\circ} \mathrm{C}$, whereas SOFCs are preferred for distributed electricity generation because they operate at approximately $850^{\circ} \mathrm{C}$, providing high-

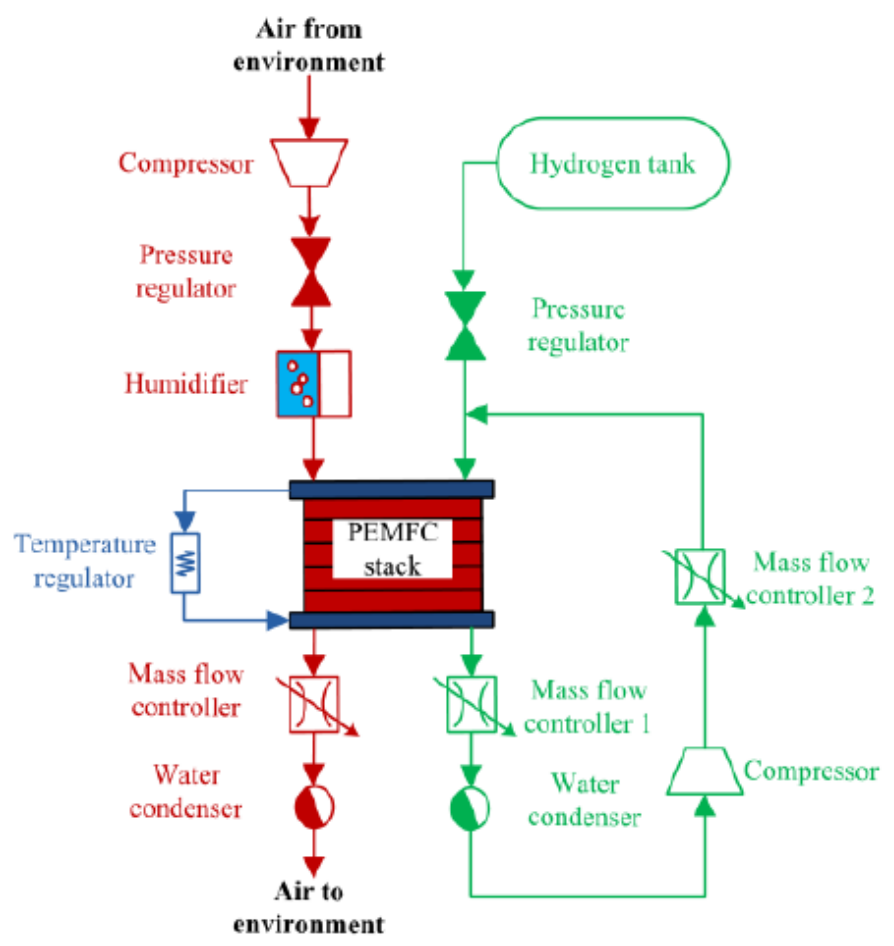

Figure 18: Schematic of the PEMFC system [51].

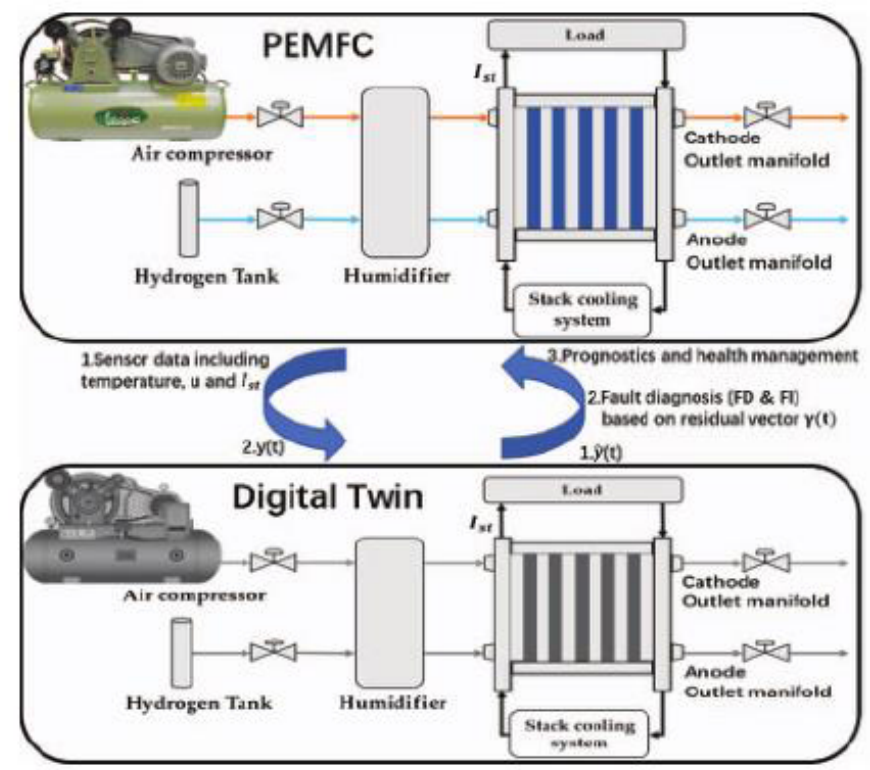

Figure 19: Implementation of DT-based fault diagnosis in PEMFC systems [53]. 
quality waste heat to recover in cogeneration and bottoming cycles [54]. The size and scale of solid oxide fuel cell systems are often large, which presents operational challenges. In [55], Jia-lin Kang et al. proposed a SOFC digital twin model amplification process based on a $25 \mathrm{~kW}$ SOFC real power plant to demonstrate the dynamic auxiliary results of the digital twin model of the $25 \mathrm{~kW}$ plant-scale SOFC system. In the scale-up process, the data from the $1 \mathrm{~kW}$ SOFC pilot plant were used to analyze the reliability and electrode parameters and develop a digital twin model that matches actual conditions at the plant. The scaleup digital twin model is applied to a $25 \mathrm{~kW}$ SOFC system. The accuracy of DT model applied to field operation prediction is verified by steady-state data. SOFC scale-up flowchart is shown in Figure 20.

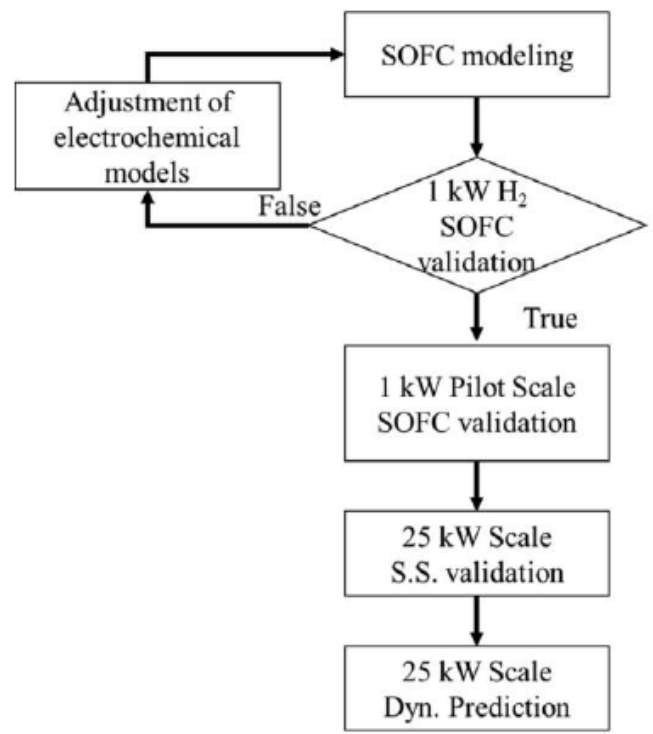

Figure 20: SOFC scale-up flowchart (S.S. indicates static state and Dyn. indicates dynamic state) [55].

The Industrial Internet of Things plays an important role in renewable energy storage systems. It can automatically control the power supply of renewable energy in real time through the big data analysis of cloud platform through the shared data of smart electricity meters. Control the energy storage equipment to supply power to the power grid in the peak period, and store the energy generated by the renewable energy generation system in the energy storage battery in the peak period. It can also intelligently monitor the industrial automation manufacturing process of energy storage batteries. For example, loT sensors can collect battery parameters on the production line and send them to the DT model for virtual simulation of charging and discharging process, and compare the simulation results with the charging and discharging process of standard energy storage battery to judge whether the produced battery is qualified.

\section{SUMMARIES AND TRENDS}

\subsection{Technical Advantages and Disadvantages}

Digital twin technology is a type of virtual simulation technology which constructs and simulates a virtual model of physical object or physical process. It has many advantages and disadvantages. The advantages of DT technique are described below:

1) Remote online detection: DT technology integrates various advanced technologies, such as Internet of Things technology, artificial intelligence algorithm, etc. DT technology can use a variety of advanced sensors for on-site detection and acquisition of equipment running status data. These data are analyzed and processed through the Internet of Things technology and big data analysis based on artificial intelligence algorithms, and the feedback results are sent to the remote monitoring platform for staff to check.

2) Fault prediction: DT technology can compare current device status data with historical data to analyze residuals and fault thresholds. Then judge whether failure will occur, and predict the time of failure in advance.

3) High security: DT technology can establish a virtual model of physical objects or entities, and the staff can conduct operation simulation in the virtual model, observe and record the simulation results and apply the most effective and safe operation to the actual equipment.

4) Wide application: DT technology can be applied to any stage of the electrical equipment life cycle, including design, production and service stages. Product design, production process, operation and maintenance (O\&M) can be improved through the feedback of information in each stage.

5) Reduce O\&M costs: DT technology can reduce manual inspection costs in some remote areas and improve work efficiency by predicting maintenance equipment and maintenance time.

6) Visualization of the running state of the equipment: DT technology can display the running 
process and status data of the power equipment using three-dimensional technical means through real-time data interaction with physical objects.

The disadvantages of DT technology are introduced as follows:

1) The concept of DT technology has not been unified yet: due to the lack of a unified DT model framework based on recognized concepts, digital twin models of various electrical equipment are different, and it is very difficult to integrate and refer to online monitoring data methods of other equipment.

2) Limited application examples: At present, researches on DT technology mainly focus on condition monitoring, fault prediction and fault diagnosis for a single individual, with few application examples of DT technology for the entire life cycle of electrical equipment. DT technology does not achieve full traceability, real-time sharing, and information interaction throughout the life cycle of the device.

3) A large number of sensors are required: Due to the need to collect a large number of parameter data for real-time monitoring of the state of electrical equipment, the number of sensors required also increases.

4) Large amount of data processing: Because DT technology requires real-time data interaction between physical objects and virtual entities, the amount of data processed by the system grows rapidly over time, and the amount of data is directly proportional to the processing cost. Therefore, how to simplify data is also one of the problems faced by DT technology.

\subsection{Development Trends}

By reviewing the applications of DT technology in renewable energy system, development trends are primarily focused on the six aspects below:

1) Development of advanced integrated sensors: Because a single type of sensor is difficult to meet the demand of DT online monitoring system for real-time complex information of power equipment, and integrated sensor system can collect all kinds of information from a variety of sensors in the same location, which is the premise of the development of DT technology concept in practice. Nikolaos P. Preve et al. proposed the concept of a new SensorWeb network consisting of wireless, internally communicating, spatially distributed sensors that can be easily deployed to monitor and probe the surrounding environment for accurate measurements and better data management [56].

2) Simplification of calculation data: The amount of data collected by sensors increases with time. The more data is transmitted each time, the higher the cost of data processing. Here are two possible approaches. One is to organize, process and store data in advance by establishing non-relational databases and introducing big data methods [27]. Non-relational database can improve the efficiency of data query, reduce the number of data store repeats and optimize the relationship between database tables. Big data approach can optimize data processing speed. Another method is to firstly divide the whole network into several data related clusters according to spatial correlation. Then, a data acquisition tree is established to collect compressed data in a mixed manner. Finally, the data reconstruction problem is modeled as a set of sparse problems and solved by ADMM algorithm[57].

3) Establishment of a unified DT conceptual framework: At present, the DT technology applied to $\mathrm{RE}$ system is still in the development stage, there is no unified DT concept, and the digital model based on DT technology applied to various electrical equipment is not unified. The future research direction is to promote the standardized application of DT technology in various physical objects in RE system, including power generation system, transmission and distribution equipment and energy storage system, and carry out data interaction under the unified DT conceptual framework.

4) Full life cycle bidirectional traceability of physical objects: DT technology can penetrate the full life cycle and value chain of physical objects to achieve full life cycle traceability of physical objects, and record the data of the design, production, installation and operation process of physical objects to visualize the $3 \mathrm{D}$ display. At the same time, the possible future running status of physical objects can be predicted and evaluated through real-time information interaction between virtual entities and physical objects.

5) Feedback regulation for the whole life cycle of physical objects: The measurement parameters of the product in the production process are fed back to the design stage for optimizing the production process by comparing the measurement parameters with the 
design parameters, and the experience of users in the operation stage is fed back to the design stage for improving the design of the next generation of products.

6) Building block DT model group based on the unified DT conceptual framework: Under the unified DT conceptual framework, several or a group of simulation models are created and deployed in various stages of the life cycle of physical objects, and these models have a clear purpose and validity range [58]. During this life cycle, new models with expected functionality can be added to the model group at any time, and a complete DT model group can be broken down into several smaller models for independent analysis.

\section{CONCLUSION}

This paper briefly introduces the application of digital twin technology in renewable energy generation, transmission, conversion and storage systems. DT technology is a very efficient and reliable virtual simulation method, which can realize real-time data interaction between virtual entities and physical objects. In wind power generation, photovoltaic power generation and wave power generation, DT technology can reduce operation and maintenance costs, improve the reliability of key parts of the operation and power generation device status monitoring; In power transformer, GIS and cable transmission and transformation equipment, DT technology can be remote online detection, predictive maintenance and fault diagnosis; In energy storage systems, DT technology can be used for performance degradation assessment, fault diagnosis and virtual operation simulation of batteries. In addition, DT technology integrated the Industrial Internet of Things technology, artificial intelligence algorithms and other advanced technology, can achieve a variety of renewable energy system electrical equipment in the life cycle of each stage of virtual simulation and can be visualized through three-dimensional technical means. At present, the applications of DT technology in the design and retire stages of whole life cycle digitalization of physical objects related to renewable energy systems are currently limited, but with the unification of DT conceptual framework and future development of DT technology, DT technology has great development potential in the application of the whole life cycle digitalization of physical objects.

\section{ACKNOWLEDGEMENTS}

This work was supported in part by the National Natural Science Foundation of China under Grant 52077063, in part by Science and Technology Program of Changsha under Grant kq2004006, in part by Open Fund of State Key Laboratory of Electrical Insulation for Power Equipment (Xi'an Jiaotong University) under Grant EIPE20202.

\section{LIST OF ACRONYMS}

\begin{tabular}{|c|c|}
\hline Abbreviations & Original text \\
\hline $\mathrm{CM}$ & Condition monitoring \\
\hline DMS & Data, model and service \\
\hline DT & Digital twin \\
\hline DTS & Digital twin shop floor \\
\hline EUR & Eurodollar \\
\hline GIS & Gas insulated switchgear \\
\hline IloT & Industrial Internet of things \\
\hline loT & Internet of things \\
\hline LIB & Lithium-ion batteries \\
\hline MBD & Model based definition \\
\hline MRE & Marine energy \\
\hline O\&M & Operation and maintenance \\
\hline PD & Partial discharge \\
\hline PEMFC & Proton exchange membrane fuel cell \\
\hline PHM & Prognostics and health management \\
\hline PTO & Power take-off \\
\hline PV & Photovoltaic \\
\hline RGB & Red, green and blue \\
\hline RE & Renewable energy \\
\hline SOFC & Solid oxide fuel cell \\
\hline SSCPL & Series solar cell production line \\
\hline UV & Ultra violet \\
\hline WEC & Wave energy converter \\
\hline
\end{tabular}




\section{REFERENCES}

[1] Y. He et al., "An overview of acoustic emission inspection and monitoring technology in the key components of renewable energy systems," Mechanical Systems and Signal Processing, vol. 148, p. 107146, 2021. https://doi.org/10.1016/i.ymssp.2020.107146

J. Carroll, A. McDonald, and D. McMillan, "Failure rate, repair time and unscheduled O\&M cost analysis of offshore wind turbines," Wind Energy, vol. 19, no. 6, pp. 1107-1119, 2016. https://doi.org/10.1002/we.1887

[3] W. Vachon, "Long-term O\&M costs of wind turbines based on failure rates and repair costs," in Proceedings WINDPOWER, American Wind Energy Association annual conference, Portland, OR, 2002, pp. 2-5.

[4] K. Sivalingam, M. Sepulveda, M. Spring, and P. Davies, "A review and methodology development for remaining useful life prediction of offshore fixed and floating wind turbine power converter with digital twin technology perspective," in 2018 2nd international conference on green energy and applications (ICGEA), 2018: IEEE, pp. 197-204. https://doi.org/10.1109/ICGEA.2018.8356292

[5] S. Zhang, S. Wang, and L. Zhao, "The Life Cycle State Evaluation of Electrical Equipment based on Digital Twins," in 2020 IEEE International Conference on High Voltage Engineering and Application (ICHVE), 2020: IEEE, pp. 1-4. https://doi.org/10.1109/ICHVE49031.2020.9279568

[6] X. Qu, Y. Song, D. Liu, X. Cui, and Y. Peng, "Lithium-ion battery performance degradation evaluation in dynamic operating conditions based on a digital twin model," Microelectronics Reliability, vol. 114, 2020. https://doi.org/10.1016/j.microrel.2020.113857

[7] Y. Wang, G. Zhang, R. Chen, Z. Liu, and R. Qiu, "Analysis of digital twin application of urban rail power supply system for energy saving," presented at the 2021 IEEE 1st International Conference on Digital Twins and Parallel Intelligence (DTPI), 2021.

https://doi.org/10.1109/DTPI52967.2021.9540127

[8] M. Liu, S. Fang, H. Dong, and C. Xu, "Review of digital twin about concepts, technologies, and industrial applications," Journal of Manufacturing Systems, vol. 58, pp. 346-361, 2021.

https://doi.org/10.1016/j.jmsy.2020.06.017

[9] A. Khalyasmaa, S. Eroshenko, D. Shatunova, A. Larionova, and A. Egorov, "Digital twin technology as an instrument for increasing electrical equipment reliability," in IOP Conference Series: Materials Science and Engineering, 2020, vol. 836, no. 1: IOP Publishing, p. 012005. https://doi.org/10.1088/1757-899X/836/1/012005

[10] S. Bhattacharjee and C. Nandi, "Implementation of industrial internet of things in the renewable energy sector," in The Internet of Things in the Industrial Sector: Springer, 2019, pp. 223-259.

https://doi.org/10.1007/978-3-030-24892-5 10

[11] Y. Zheng, S. Yang, and H. Cheng, "An application framework of digital twin and its case study," Journal of Ambient Intelligence and Humanized Computing, vol. 10, no. 3, pp. 1141-1153, 2018.

https://doi.org/10.1007/s12652-018-0911-3

[12] F. Tao, Y. Cheng, J. Cheng, M. Zhang, W. Xu, and Q. Qi, "Theories and technologies for cyber-physical fusion in digital twin shop-floor," 2017.

[13] F. Tao, Y. Cheng, L. Zhang, and AY. Nee, "Advanced manufacturing systems: socialization characteristics and trends," Journal of Intelligent Manufacturing, vol. 28, no. 5, pp. 1079-1094, 2017. https://doi.org/10.1007/s10845-015-1042-8

[14] F. Tao, M. Zhang, J. Cheng, and Q. Qi, "Digital twin workshop: a new paradigm for future workshop," Computer
Integrated Manufacturing Systems, vol. 23, no. 1, pp. 1-9, 2017.

[15] J. Tang, S. Soua, C. Mares, and TH. Gan, "An experimental study of acoustic emission methodology for in service condition monitoring of wind turbine blades," Renewable Energy, vol. 99, pp. 170-179, 2016.

https://doi.org/10.1016/j.renene.2016.06.048

[16] W. Yang and S. W. Tian, "Research on a power quality monitoring technique for individual wind turbines," Renewable Energy, vol. 75, pp. 187-198, 2015.

https://doi.org/10.1016/j.renene.2014.09.037

[17] E. Branlard, D. Giardina, and CS. Brown, "Augmented Kalman filter with a reduced mechanical model to estimate tower loads on a land-based wind turbine: a step towards digital-twin simulations," Wind Energy Science, vol. 5, no. 3, pp. 1155-1167, 2020.

\section{https://doi.org/10.5194/wes-5-1155-2020}

[18] F. Pimenta, J. Pacheco, C. Branco, C. Teixeira, and F. Magalhães, "Development of a digital twin of an onshore wind turbine using monitoring data," in Journal of Physics: Conference Series, 2020, vol. 1618, no. 2: IOP Publishing, p. 022065.

https://doi.org/10.1088/1742-6596/1618/2/022065

[19] S. S. Johansen, "On developing a digital twin for fault detection in drivetrains of offshore wind turbines," NTNU, 2018.

[20] S. Wakayama and A. Mizutani, "AE Analysis of Damage Process in Thin Film Solar Cells under Mechanical Strain " presented at the 29th European Conference on Acoustic Emission Testing, Wien 2010.

[21] H. Tazawa, T. Sakai, and S. Wakayama, "Characterization of Damage in a-Si/a-SiGe Flexible Solar Cells under Mechanical Strain by $\mathrm{AE}$ Technique and Lock-in Thermography," presented at the 28th European Photovoltaic Solar Energy Conference and Exhibition, Paris, 2013.

[22] Y. Kishi et al., "Ultralight flexible Amorphous silicon solar cell and its application to an airplane," Solar Energy Materials, vol. 23, no. 2-4, pp. 312-318, 1991.

https://doi.org/10.1016/0165-1633(91)90135-8

[23] O. Mori et al., "First Solar Power Sail Demonstration by IKAROS," Transaction on The Japan Society for Aeronautical and Space Sciences, Aerospace Technology, vol. 8, no. 27, pp. To_4_25-To_4_31, 2010.

https://doi.org/10.2322/tastj.8.To_4_25

[24] B. Lu and X. Zhou, "Quality and reliability oriented maintenance for multistage manufacturing systems subject to condition monitoring," Journal of Manufacturing Systems, vol. 52, pp. 76-85, 2019.

https://doi.org/10.1016/j.jmsy.2019.04.003

[25] MJ. Hossain et al., "A Comprehensive Methodology to Evaluate Losses and Process Variations in Silicon Solar Cell Manufacturing," IEEE Journal of Photovoltaics, vol. 9, no. 5, pp. 1350-1359, 2019.

https://doi.org/10.1109/JPHOTOV.2019.2926628

[26] FQ. Pei, YF. Tong, MH. Yuan, K. Ding, and XH. Chen, "The digital twin of the quality monitoring and control in the series solar cell production line," Journal of Manufacturing Systems, vol. 59, pp. 127-137, 2021.

https://doi.org/10.1016/j.jmsy.2021.02.001

[27] L. Massel, N. Shchukin, and A. Cybikov, "Digital twin development of a solar power plant," in E3S Web of Conferences, 2021, vol. 289: EDP Sciences.

https://doi.org/10.1051/e3sconf/202128903002

[28] SK. Andryushkevich, SP. Kovalyov, and E. Nefedov, "Composition and application of power system digital twins 
based on ontological modeling," in 2019 IEEE 17th International Conference on Industrial Informatics (INDIN), 2019, vol. 1: IEEE, pp. 1536-1542. https://doi.org/10.1109/INDIN41052.2019.8972267

[29] R. Asimov, S. Chernoshey, I. Kruse, and V. Osipovich, "Digital twin in the Analysis of a Big Data," Big Data and Advanced Analytics, no. 4, pp. 70-79, 2018.

[30] L. Bai, Y. Zhang, H. Wei, J. Dong, and W. Tian, "Digital Twin Modeling of a Solar Car Based on the Hybrid Model Method with Data-Driven and Mechanistic," Applied Sciences, vol. 11 , no. $14,2021$. https://doi.org/10.3390/app11146399

[31] J. Walsh, I. Bashir, P. R. Thies, L. Johanning, and P. Blondel, "Acoustic emission health monitoring of marine renewables: Illustration with a wave energy converter in Falmouth Bay (UK)," in OCEANS 2015-Genova, 2015: IEEE, pp. 1-7. https://doi.org/10.1109/OCEANS-Genova.2015.7271455

[32] J. Walsh, I. Bashir, J. K. Garrett, PR. Thies, P. Blondel, and L. Johanning, "Monitoring the condition of marine renewable energy devices through underwater acoustic emissions: Case study of a wave energy converter in Falmouth Bay, UK," Renewable Energy, vol. 102, pp. 205-213, 2017. https://doi.org/10.1016/j.renene.2016.10.049

[33] G. Reikard, B. Robertson, and JR. Bidlot, "Wave energy worldwide: Simulating wave farms, forecasting, and calculating reserves," International journal of marine energy, vol. 17, pp. 156-185, 2017. https://doi.org/10.1016/j.ijome.2017.01.004

[34] P. Qian, B. Feng, D. Zhang, X. Tian, and Y. Si, "loT-based approach to condition monitoring of the wave power generation system," IET Renewable Power Generation, vol. 13, no. 12, pp. 2207-2214, 2019. https://doi.org/10.1049/iet-rpg.2018.5918

[35] A. Cichoń and P. Berger, "Possibility of using acoustic emission method for testing load tap changers during normal operation of the transformer," presented at the 2014 International Conference on High Voltage Engineering and Application, Poznan, 2014. https://doi.org/10.1109/ICHVE.2014.7035479

[36] Y. Yang et al., "State Evaluation of Power Transformer Based on Digital Twin," in 2019 IEEE International Conference on Service Operations and Logistics, and Informatics (SOLI), 2019: IEEE, pp. 230-235. https://doi.org/10.1109/SOLI48380.2019.8955043

[37] IE. Kolesnikov, AV. Korzhov, and KE. Gorshkov, "Digital Program for Diagnosing the Status of a Power Transformer," in 2020 Global Smart Industry Conference (GloSIC), 2020: IEEE, pp. 315-321.

https://doi.org/10.1109/GloSIC50886.2020.9267867

[38] W. Boeck, "Insulation Co-Ordination of GIS, Return of Experience, On Site Tests and Diagnostic Techniques," Electra, no. 176, pp. 67-97, 1998.

[39] Z. Jiang, Y. Guo, and Z. Wang, "Digital twin to improve the virtual-real integration of industrial loT," Journal of Industrial Information Integration, vol. 22, 2021. https://doi.org/10.1016/j.jii.2020.100196

[40] AM. Madni, CC. Madni, and SD. Lucero, "Leveraging digital twin technology in model-based systems engineering," Systems, vol. 7, no. 1, p. 7, 2019.

https://doi.org/10.3390/systems7010007

[41] B. Pang, B. Zhu, X. Wei, S. Wang, and R. Li, "On-line monitoring method for long distance power cable insulation," IEEE Transactions on Dielectrics and Electrical Insulation, vol. 23, no. 1, pp. 70-76, 2016. https://doi.org/10.1109/TDEl.2015.004995

[42] Yq. Hao, YI. Cao, Q. Ye, Hw. Cai, and Rh. Qu, "On-line temperature monitoring in power transmission lines based on Brillouin optical time domain reflectometry," OptikInternational Journal for Light and Electron Optics, vol. 126, no. 19 , pp. 2180-2183, 2015. https://doi.org/10.1016/j.ijleo.2015.05.111

[43] X. Chen, J. Smit, and S. Meijer, "Investigation on insulation reliability of $380 \mathrm{kV}$ XLPE cable systems," in 2011 Electrical Insulation Conference (EIC). 2011: IEEE, pp. 434-438. https://doi.org/10.1109/EIC.2011.5996193

[44] O. Kähler, S. Hochstöger, G. Kemper, and J. Birchbauer "Automating powerline inspection: A novel multisensor system for data analysis using deep learning," The International Archives of Photogrammetry, Remote Sensing and Spatial Information Sciences, vol. 43, pp. 747-754, 2020. https://doi.org/10.5194/isprs-archives-XLIII-B4-2020-747$\underline{2020}$

[45] W. He et al., "Research on the Application of Digital Twin Technique in High Voltage Cable," in 2020 4th International Conference on Power and Energy Engineering (ICPEE), 2020: IEEE, pp. 90-93 https://doi.org/10.1109/ICPEE51316.2020.9311058

[46] B. Dunn, H. Kamath, and JM. Tarascon, "Electrical energy storage for the grid: a battery of choices," Science, vol. 334, no. 6058 , pp. 928-935, 2011.

https://doi.org/10.1126/science.1212741

[47] B. Wu, WD. Widanage, S. Yang, and X. Liu, "Battery digital twins: Perspectives on the fusion of models, data and artificial intelligence for smart battery management systems," Energy and Al, vol. 1, p. 100016, 2020. https://doi.org/10.1016/j.egyai.2020.100016

[48] T. Chen et al., "Applications of lithium-ion batteries in gridscale energy storage systems," Transactions of Tianjin University, vol. 26, no. 3, pp. 208-217, 2020.

https://doi.org/10.1007/s12209-020-00236-w

[49] Y. Peng, X. Zhang, Y. Song, and D. Liu, "A low cost flexible digital twin platform for spacecraft lithium-ion battery pack degradation assessment," in 2019 IEEE International Instrumentation and measurement technology conference (I2MTC), 2019: IEEE, pp. 1-6. https://doi.org/10.1109//2MTC.2019.8827160

[50] L. Merkle, AS. Segura, JT. Grummel, and M. Lienkamp, "Architecture of a digital twin for enabling digital services for battery systems," in 2019 IEEE international conference on industrial cyber physical systems (ICPS), 2019: IEEE, pp. 155-160. https://doi.org/10.1109/ICPHYS.2019.8780347

[51] Z. Li et al., "Online implementation of SVM based fault diagnosis strategy for PEMFC systems," Applied energy, vol. 164, pp. 284-293, 2016.

https://doi.org/10.1016/j.apenergy.2015.11.060

[52] B. Wang, G. Zhang, H. Wang, J. Xuan, and K. Jiao, "Multiphysics-resolved digital twin of proton exchange membrane fuel cells with a data-driven surrogate model," Energy and Al, vol. 1, p. 100004, 2020. https://doi.org/10.1016/j.egyai.2020.100004

[53] J. Zhao and J. Zhu, "A digital twin approach for fault diagnosis in PEM fuel cell systems," in 2021 IEEE 1st International Conference on Digital Twins and Parallel Intelligence (DTPI), 2021: IEEE, pp. 168-171. https://doi.org/10.1109/DTPI52967.2021.9540157

[54] P. Costamagna et al., "Fault diagnosis strategies for SOFCbased power generation plants," Sensors, vol. 16, no. 8, p. 1336, 2016.

https://doi.org/10.3390/s16081336

[55] JL. Kang, CC. Wang, DSH. Wong, SS. Jang, and CH. Wang, "Digital twin model and dynamic operation for a plant-scale solid oxide fuel cell system," Journal of the Taiwan Institute of Chemical Engineers, vol. 118, pp. 60-67, 2021. https://doi.org/10.1016/j.jtice.2021.01.001

[56] NP. Preve and EN. Protonotarios, "An integrated sensor web grid cyberimplementation for environmental protection," IEEE Sensors Journal, vol. 11, no. 9, pp. 1787-1794, 2011. https://doi.org/10.1109/JSEN.2011.2104949 
[57] G. Li et al., "Energy efficient data collection in large-scale internet of things via computation offloading," IEEE Internet of Things Journal, vol. 6, no. 3, pp. 4176-4187, 2018. https://doi.org/10.1109/JIOT.2018.2875244
[58] S. Boschert, C. Heinrich, and R. Rosen, "Next generation digital twin," in Proc. tmce, 2018, vol. 2018: Las Palmas de Gran Canaria, Spain, pp. 7-11.

Received on 27-10-2021

Accepted on 25-11-2021

Published on 20-12-2021

DOI: https://doi.org/10.31875/2409-9694.2021.08.4

(C) $2021 \mathrm{Li}$ and He; Licensee Zeal Press.

This is an open access article licensed under the terms of the Creative Commons Attribution Non-Commercial License (http://creativecommons.org/licenses/by-nc/3.0/), which permits unrestricted, non-commercial use, distribution and reproduction in any medium, provided the work is properly cited. 